\title{
A note on the introduction of Hilbert's Grundlagen der Geometrie
}

\section{Giorgio Venturi}

University of Campinas - UNICAMP

Department of Philosophy

Campinas, Brazil

gio.venturi@gmail.com

Article info

CDD: 516.2

Received: 05.04.2017; Revised: 15.06.2017; Accepted: 16.06.2017

DOI: http://dx.doi.org/10.1590/0100-6045.2017.V40N2.GV

Keywords
Hilbert
geometry
independence
simplicity
Grundlagen der Geometrie

\begin{abstract}
We present and discuss a change in the introduction of Hilbert's Grundlagen der Geometrie between the first and the subsequent editions: the disappearance of the reference to the independence of the axioms.

We briefly outline the theoretical relevance of the notion of independence in Hilbert's work and we suggest that a possible reason for this disappearance is the discovery that Hilbert's axioms were not, in fact, independent. In the end we show how this change gives textual evidence for the connection between the notions of independence and simplicity.
\end{abstract}

Manuscrito - Rev. Int. Fil., Campinas, v.40, n.2, pp.5-17, abr.jun. 2017. 


\section{Introduction}

In this brief note we would like to discuss a philological observation that results from comparing the introductions of the various editions of Hilbert's Grundlagen der Geometrie. This observations deals with the independence of the axioms that Hilbert proposed for the foundations of geometry. The issue of independence was discussed already by Hilbert's contemporaries. Indeed, although the groups of axioms of the Grundlagen der Geometrie were mutually independent, ${ }^{1}$ this was not the case for the single axioms that constitute a particular group; as shown for example by E. Moore in Moore (1902). In discussing the issue of independence, we will outline the theoretical importance of this notion in Hilbert's foundational work, together with its role in the application of the axiomatic method. ${ }^{2}$

\section{Two different versions of the introduction}

The philological observation we intend to discuss originates from collating the introduction of the Festschrift, that is the first edition of the Grundlagen der Geometrie ${ }^{3}$ presented for the unveiling of a statue of Gauss and Weber in Göttingen in 1899, and those of the subsequents editions. We start by reporting here the introduction of Hilbert (1902a): the first English edition of the Foundations of Geometry that consists of the translation of the Festschrift by E. J. Townsend, issued right before the second German edition of the Grundlagen der Geometrie.

Geometry, like arithmetic, requires for its logical development

\footnotetext{
${ }^{1}$ Indeed, viewing each group as the conjunction of its axioms, it is not possible to deduce one from the others.

${ }^{2}$ It is important to stress the difference between the axiomatization of a theory - that we consider at the par with its formalization - and the application of the axiomatic method. See Majer (2006) on this particular topic.

${ }^{3}$ By Grundlagen der Geometrie we mean the German editions from the second onward. When textual reference is needed, without loss of precision we refer to Hilbert (1903), since the introduction of the second and subsequent German editions are alike.
}

Manuscrito - Rev. Int. Fil., Campinas, v.40, n.2, pp.5-17, abr.jun. 2017. 
only a small number of simple, fundamental principles. These fundamental principles are called the axioms of geometry. The choice of the axioms and the investigation of their relations to one another is a problem which, since the time of Euclid, has been discussed in numerous excellent memoirs to be found in the mathematical literature. This problem is tantamount to the logical analysis of our intuition of space.

The following investigation is a new attempt to choose for geometry a simple and complete set of independent axioms and to deduce from these the most important geometrical theorems in such a manner as to bring out as clearly as possible the significance of the different groups of axioms and the scope of the conclusions to be derived from the individual axioms. ${ }^{4}$

In the preface of Hilbert (1902a) Townsend explained that he also included the additions that Hilbert authorized in the first French edition (Hilbert (1900)), of which the second paragraph of the introduction reads as follows.

La recherche qui suit est un nouvel essai dont le but est d'établir la Géométrie sur un système SIMPLE et COMPLET d'axiome INDEPEND ANTES et de déuire de ceux-ci les principaux théorèmes géométriques, de telle sort que le rôle des divers groupe d'axiomes et la portée des conclusions que l'on tire des axiomes

${ }^{4}$ Hilbert (1902a), p. 2. The emphasis in the text is not mine. The introduction of Hilbert (1899) reads as follows 'Die Geometrie bedarf - ebenso wie die Arithmetik - zu ibrem folgerichtigen Aufbau nur weniger und einfacher Grundthatsachen. Diese Grundthatsachenheissen Axiome der Geometrie. Die Aufstellung der Axiome der Geometrie und die Erforschung ibres Zusammenhanges ist eine Aufgabe, die seit Euklid in zablreichen vortreflichen Abbandlungen der mathematischen Literatur sich erörtert findet. Die bezeichnete Aufgabe läuft auf die logische Analyse unserer räumlichen Anschauung hinaus.

Die vorliegende Untersuchung ist ein neuer Versuch, für die Geometrie ein e in $f$ a $c$ b es und vol l s tänd ige system von einander $u n$ a b bäng $i g$ e $r$ Axiome aufzustellen und aus denselben die wichtigsten geometrischen Sätze in der Weise abzuleiten, daß dabei die Bedeutung der verschiedenen Axiomgruppen und die Tragweite der aus den einzelnen Axiomen zu ziehenden Folgerungen möglichst klar zutage tritt.'

Manuscrito - Rev. Int. Fil., Campinas, v.40, n.2, pp.5-17, abr.jun. 2017. 
individuels soient mis en pleine lumière autant qu'il est possible .

Hilbert's work on the foundations of geometry started almost ten years before the Festschrift ${ }^{6}$ and in the subsequent editions the Grundlagen der Geometrie received many important additions and modifications. ${ }^{7}$ In order to discuss a small - but we believe not minor - change that occurred between the first German edition (Hilbert (1899)) and the second (Hilbert (1903)), we report the introduction of Hilbert (1971a): the first edition of the second English translation by L. Unger, from 1971, translated from the tenth German edition (Hilbert (1968)).

Geometry, like arithmetic, requires only a few and simple principles for its logical development. These principles are called the axioms of geometry. The establishment of the axioms of geometry and the investigation of their relationships is a problem which has been treated in many excellent works of the mathematical literature since the time of Euclid. This problem is equivalent to the logical analysis of our perception of space.

This present investigation is a new attempt to establish for geometry a complete, and as simple as possible, set of axioms and to deduce from them the most important geometric theorems in such a way that the meaning of the various groups of axioms, as well as the significance of the conclusions that can be drawn from the individual axioms, come to light. ${ }^{8}$

\footnotetext{
${ }^{5}$ Hilbert (1900), p. 6. The capital letters are not mine.

${ }^{6}$ It indeed consists of a more elaborated version of the content of a series of lectures on geometry that Hilbert gave at the University of Göttingen between 1891 and 1899. See Hallett and Majer (2004) for a detailed account of the connections between the Festschrift and the preceding lectures notes.

${ }^{7}$ See Hallett and Majer (2004) and Hilbert (1999) for an outline of the major changes between the different editions of the Festschrift. Another more complete critical edition of Hilbert (1899) is Hilbert (1971b), that we will discuss below.

${ }^{8}$ Hilbert (1971a), p. 2. In German, in Hilbert (1903), the introduction reads as follows:
}

Manuscrito - Rev. Int. Fil., Campinas, v.40, n.2, pp.5-17, abr.-jun. 2017. 
The difference we want to discuss' is the presence of the adjective ' $u n$ abbängiger' in the Festschrift - and consequently the statement of independence of the axioms in the introduction of the first French and English editions - and its disappearance in the introduction of all subsequent German editions, as we can see in the second English translation, taken from the tenth German edition. To our knowledge this difference has been noticed in few places in the literature ${ }^{10}$, but has never been discussed. ${ }^{11}$ In the last section

'Die Geometrie bedarf - ebenso wie die Arithmetik - zu ibrem folgerichtigen Aufbau nur weniger und einfacher Grundsätze. Diese Grundsätze heißen Axiome der Geometrie. Die Aufstellung der Axiome der Geometrie und die Erforschung ibres Zusammenhanges ist eine Aufgabe, die seit Euklid in zablreichen vortrefflichen Abhandlungen der mathematischen Literatur sich erörtert findet. Die bezeichnete Aufgabe läuft auf die logische Analyse unserer räumlichen Anschauung binaus.

Die vorliegende Untersuchung ist ein neuer Versuch, für die Geometrie ein vo llstä $n d i$ ges und $m$ öglichst e in fac be system von Axiomen aufzustellen und aus denselben die wichtigsten geometrischen Sätze in der Weise abzuleiten, daß dabei die Bedeutung der verschiedenen Axiomgruppen und die Tragweite der aus den einzelnen Axiomen zu ziehenden Folgerungen möglichst klar zutage tritt.'

${ }^{9}$ We will not discuss the use of the term Grundthatsachen, in Hilbert (1899), instead of the term Grundsätze, as in Hilbert (1903), in the first two sentences, because we do not think it has a theoretical relevance.

${ }^{10}$ The places where we could find an indication of this difference are: in Toepell's notes of Hilbert (1999), p. 294: Absatz 2 enthielt in $1 G G$ noch die Formulierung ‘... für die Geometrie ein einfaches und vollständiges System voneinander unabhängiger Axiome aufzustellen ...', was ab 2GG abgeschwächt wurde'; in Peckhaus (1990) p. 23: 'In der 2. Aufl. (1903, 1) wird 'Grundsätze' statt 'Grundthatsachen' gesetzt, und statt 'ein einfaches und vollständiges System voneinander unabhängiger Axiome' heißt es 'vollständiges und möglichst einfaches System von Axiomen"; and in the 1971 critical edition of the Festschrift, by Paul Rossier (Hilbert (1971b)). There are two major problems in Rossier's contribution to this topic. In first place the relevant comparative note of the introduction (reported as in the second German edition: Hilbert (1903)), that reads as follows: ' 1 'e éd.: 'un système d'axiomes complete, aussi simple que possible et independants'. Adjonction de : 'independants", is not completely correct. The reason being that in passing from the Festschrift to the second German edition Hilbert did not only eliminated the adjective 'independent', but also made the reference to simplicity not only with the adjective 'simple', but with the expression 'as simple as possible'. As we will argue later, we believe that this point has a theoretical relevance. Secondly, Rossier's critical edition does not consider also the English editions, but only the German ones. As we will show in last section this absence precludes a complete understanding of the problem.

${ }^{11} \mathrm{Of}$ course we are not claiming that the evolution of Hilbert's concerns on the issue of

Manuscrito - Rev. Int. Fil., Campinas, v.40, n.2, pp.5-17, abr.jun. 2017. 
of this article we will motivate and interpret the disappearance of the term 'unabbängiger' in passing from Hilbert (1899) to Hilbert (1903). Before that we will briefly outline the importance that the notion of independence had in Hilbert's axiomatics.

\section{The theoretical value of independence}

In this section we would like to discuss briefly some among the many reasons that make easy to recognize the centrality of the notion of independence in Hilbert's view at the time of the foundations of geometry. The importance of the independence of the axioms is stressed also in Hilbert's unpublished lectures. ${ }^{12}$

1. The reference to independence is placed in the introduction of the Festschrift, where Hilbert outlines the main properties of the basic principles of an axiomatic system. Moreover, the end of the introduction also explains the reason of its importance: "to bring out as clearly as possible the significance of the different groups of axioms and the scope of the conclusions to be derived from the individual axioms". Indeed, the mutual independence of the (groups of) axioms allow to understand the necessity, and therefore the precise conceptual range, of the basic principles on which geometry is based. In a complementary way completeness is a property of the axiomatic system meant "to deduce from these the most important geometrical theorems". In other terms completeness acts like a sufficient condition for an appropiate axiomatization of geometry. Therefore, independence and completeness are the balanced requisites to impose to a system in or-

\footnotetext{
independence has never been discussed. For a general discussion of this topic in the context of the different editions of the Grundlagen der Geometrie the reader may consult Toepell's 'Anmerkungen des Herausgebers' in the 14th edition of Hilbert's Grundlagen: Hilbert (1999).

${ }^{12}$ For example, in the 1902 lectures entitled Grundlagen der Geometrie (Hilbert (1902b)), we find three condition that an axiomatic system should fulfill: completeness, independence and coherence.
}

Manuscrito - Rev. Int. Fil., Campinas, v.40, n.2, pp.5-17, abr.jun. 2017. 
der to give necessary and sufficient conditions ${ }^{13}$ for the proof of its theorems. ${ }^{14}$.

2. Independence - and also simplicity - are not only mathematical desiderata, but they have a theoretical importance with respect to the way Hilbert conceived the foundation of a science in that period: a deepening of the foundation and a logical analysis of our intuitions. It is then instructive to notice the parallel between this foundational conception and the regressive analysis used to give foundations to a science ${ }^{15}$. Indeed if two axioms are not independent, then the axiomatic method (i.e. the deepening of the foundations) may still proceed in discovering more basic principles of a theory. Therefore, the need for independence - as for simplicity - does not have only a mathematical purpose, but also an epistemological value. In other words, the independence of two axioms (or group of axioms) is viewed as the indicator of the distinctiveness of the ideas formalized by these principles. Moreover, the parallel between regressive and axiomatic methods is such that the foundation of geometry aims at finding simple conceptual components on which this entire science can be based.

3. The notion of independence is a fundamental element for reaching the most important aim of the axiomatic investigations: to find necessary and sufficient conditions for the proof of a mathematical fact ${ }^{16}$.

\footnotetext{
${ }^{13}$ Here we keep with the ambiguity of whether the conditions are the single axioms or just the groups of axioms.

${ }^{14}$ See Venturi (2011) for a more detailed description of Hilbert's axiomatization of geometry in terms of a search for necessary and sufficient conditions for the proof of geometrical theorems and for a discussion about the Axiom of Completeness, in connection with this aspect of Hilbert's work.

${ }^{15}$ See Peckhaus (2002) for a discussion of this topic, where it is also possible to find the following quotation from Hilbert (1919), 18: 'This regressive method finds its perfect expression in what is called today "axiomatic method". This is a general method of scientific research as such, it celebrates, however, its most brilliant triumphs in mathematics.'.

${ }^{16}$ See for example Hilbert (1894), p. 8: 'Our colleague's problem is this: what are the necessary and sufficient conditions, independent of each other, which one must posit for a system of things, so that every property of these things corresponds to a geometrical fact and vice
}

Manuscrito - Rev. Int. Fil., Campinas, v.40, n.2, pp.5-17, abr.jun. 2017. 
Indeed the elucidation of necessary and sufficient conditions has the role of placing a theorem within the logical structure given by the axiomatization of a field. In this process axioms are the conditions (necessary and/or sufficient) for the proof of a theorem. Consequently axioms should not have any logical relation of dependence between them.

\section{A possible explanation}

In this last section we would like to propose a possible explanation of why Hilbert decided to eliminate the term 'unabbängig' in passing from Hilbert (1899) to Hilbert (1903).

Soon after the publication of the Festschrift Schur (Schur (1901)) and Moore (Moore (1902)) argued that the system presented in Hilbert's foundation of geometry was not composed by fully independent axioms. We can also add Veblen's article, dated January 1903 (Veblen (1903)), where interesting criticisms were addressed to the independence of Hilbert's axioms ${ }^{17}$.

As it is natural to suggest, Hilbert eliminated the reference to the independence of the axioms because of the criticism his system received on this particular respect. However, in light of the relevance that the notion of independence plays in Hilbert's axiomatic work, we believe that the elimination of the reference to independence in the introduction of Hilbert (1903) did not undermine the theoretical value of this notion. As a matter of fact the whole expositions of Hilbert's foundations of geometry shows how useful and insightful independence proofs can be.

Another reason for sustaining this reading is the presence in the first

versa, so that by means of such a system of things a complete description and ordering of all geometrical facts is possible' or Hilbert (1902/1903), p. 50: 'I understand under the axiomatical exploration of a mathematical truth [or theorem] an investigation which does not aim at finding new or more general theorems being connected with this truth, but to determine the position of this theorem within the system of known truths in such a way that it can be clearly said which conditions are necessary and sufficient for giving a foundation of this truth'.

${ }^{17}$ After Veblen (1903), Veblen will be lead to propose in 1904 (Veblen (1904)) a system of truly independent axioms.

Manuscrito - Rev. Int. Fil., Campinas, v.40, n.2, pp.5-17, abr.jun. 2017. 
English authorized translation (Hilbert (1902a)) of a note at the beginning of section 10 - whose title is 'Independence of the axiom of parallel (NonEuclidean geometry)' - that reads as follows:

The mutual independence of Hilbert's system of axioms has also been discussed recently by Schur and Moore. Schur's paper, entitled "Ueber die Grundlagen der Geometrie” appeared in Math. Annalem, Vol. 55, p. 265, and that of Moore, "On the Projective Axioms of Geometry," is to be found in the Jan. (1902) number of the Transactions of the Amer. Math. Society.Tr.

It is important to stress the fact that Hilbert (1902a) is an authorized translation that received Hilbert's approval. Therefore it is easy to argue that Hilbert was well aware of the criticism that his work had received overseas. However, there is no trace of this note neither in Hilbert (1903) - and in the subsequent German editions - nor in the second English edition (Hilbert $(1971 \mathrm{a}))^{18}$.

Another interesting observation that shows the importance of independence proofs in the Grundlagen der Geometrie can be found in the Preface of the first English edition (Hilbert (1902a)). Here Townsend, in discussing the major imports of Hilbert's work, lists in first place the following achievement: 'The mutual independence and also the compatibility of the given system of axioms is fully discussed by the aid of various new systems of geometry which are introduced'. This major contribution of Hilbert's work is stressed also by J. Sommer in his review (Sommer (1900)) of Hilbert (1899) (signed Göttingen 1899).

Among the more important points in which Professor Hilbert's memoir marks a distinct advance I wish to call particular attention to the following: [...] (2) the systematic investigation of the mutual independence of the axioms, this independence being proved by producing examples of new geometries which are

${ }^{18}$ The above note is not present in French translation (Hilbert (1900)), that dates 1900.

Manuscrito - Rev. Int. Fil., Campinas, v.40, n.2, pp.5-17, abr.jun. 2017. 
in themselves interesting; (3) the principle of not merely proving a proposition in the most simple way but indicating precisely what axioms are necessary and sufficient for the proof; ${ }^{19}$

We conclude with a consideration that we can draw from this reading of the disappearance of 'unabbängig': that of a close link between independence and simplicity. As a matter of fact, Hilbert failure to produce a system of independent axioms will push him to ask no more for 'a simple and complete set of independent axioms', but for 'a complete, and as simple as possible, set of axioms'. In other words, if the axioms are not independent, then they should be, at least, as simple as possible. This observation would indicate that the notions of simplicity and that of independence are deeply linked in Hilbert's view ${ }^{20}$.

On this particular topic, it is also interesting to consider another quotation from Sommer's review of the Festschrift.

In addition to these requirements [consistency and independence] it can be demanded of a system of axioms that it be simple, in other words, that the least possible number of propositions be used to establish and sharply circumscribe the relations between the elements, none of the axioms being redundant, i.e., deducible as a corollary from any of the others ${ }^{21}$.

Interestingly enough, a parallel between the notions of simplicity and that of independence is also discussed in Veblen (1903). However, here simplicity is a property of the basic elements of the axiomatic system and not, as in Hilbert's case, of the system itself.

The question immediately arises, is it perhaps possible to define some of the elements in the terms of the other elements? In the case our system of assumptions is clearly not as simple

\footnotetext{
${ }^{19}$ Sommer (1900), p. 289.

${ }^{20}$ See Thiele (2003) for a more general discussion about simplicity, mainly of proofs.

${ }^{21}$ Sommer (1900), p. 288.
}

Manuscrito - Rev. Int. Fil., Campinas, v.40, n.2, pp.5-17, abr.jun. 2017. 
as possible, even if not one of the axioms is deducible from the others. We have therefore, in addition to the problem of determining a set of independent axioms, the analogous problem of determining an irreducible set of elements, i.e., a system of elements such that no one of them can be defined in terms of the others $^{22}$.

We do not address here the general problem of the connection between simplicity and independence in Hilbert's view. We only suggest that the disappearance of independence from the second edition was motivated by the discovery that, in fact, the axioms of the Grundlagen were not independent, and that this modification lead Hilbert to reconsider their simplicity. Thus showing a close connection between the notions of independence and simplicity.

\section{Acknowledgments}

This research was financially supported by FAPESP grant number 2013/250954 and by the BEPE grant number 2014/25342-4.

\section{References}

Hallett, M. and Majer, U. eds. 2004. David Hilbert's lectures on the foundations of geometry, 1891-1902, Berlin Heidelberg: Springer-Verlag.

Hilbert, H. 1894. 'Die Grundlagen der Geometrie', in: Hallett, M. and Majer, U. eds. David Hilbert's lectures on the foundations of geometry, 18911902, Berlin Heidelberg: Springer-Verlag, pp. 72-123.

Hilbert, H. 1899. Grundlagen der Geometrie, Leipzig : Verlag von B. G. Teubner.

Hilbert, H. 1900. [translated by L. Laugel] Les principes fondamentaux de la géométrie, Paris : Gauthier-Villars.

${ }^{22}$ Veblen (1903), p. 306.

Manuscrito - Rev. Int. Fil., Campinas, v.40, n.2, pp.5-17, abr.jun. 2017. 
Hilbert, H. 1902a. [translated by E. J. Townsend] The foundations of geometry, Chicago : The Open Court Publishing Company.

Hilbert, H. 1902b. 'Grundlagen der Geometrie', in: Hallett, M. and Majer, U. eds. David Hilbert's lectures on the foundations of geometry, 1891-1902, Berlin Heidelberg: Springer-Verlag, pp. 540-602.

Hilbert, H. 1902/1903. 'Über den Satz von der Gleichheit der Basiswinkel im gleichschenkligen Dreieck', Proceedings of the London Mathematical Society, 35, 50-68.

Hilbert, H. 1903. Grundlagen der Geometrie, 2nd ed., Leipzig : Verlag von B. G. Teubner.

Hilbert, H. 1919. 'Natur und mathematisches Erkennen', in: Rowe, D. ed. Natur und Mathematisches Erkennen: Vorlesungen, gehalten 1919-1920 in Göttingen., Basel Boston: Birkhäuser.

Hilbert, H. 1968. Grundlagen der Geometrie, 10th ed., Stuttgart : Verlag von B. G. Teubner.

Hilbert, H. 1971a. [translated by L. Unger] The foundations of geometry, 2nd ed., Chicago : The Open Court Publishing Company.

Hilbert, H. 1971b. Les principes fondamentaux de la géométrie. Édition critique avec introduction et compléments préparée par Paul Rossier, Paris : Dunod.

Hilbert, H. 1999. Grundlagen der Geometrie, 14th ed., Stuttgart Leipzig : Verlag von B. G. Teubner.

Majer, U. 2006. 'The relation of logic and intuition in Kant's philosophy of science, particularly geometry', in: Carson, E. and Huber, R. eds. Intuition and the Axiomatic Method, Dordrecht: Springer-Verlag, pp. 47-66.

Moore, E. H. 1902. 'On the projective axioms of geometry', Transactions of the American Mathematical Society, 3, 142-158.

Manuscrito - Rev. Int. Fil., Campinas, v.40, n.2, pp.5-17, abr.-jun. 2017. 
Peckhaus, V. 1990. Hilbertprogramm und Kritische Philosophie, Göttingen, Vandenhoeck \& Ruprecht.

Peckhaus, V. 2002. 'Regressive analysis', Logical Analysis and History of Philosophy, 5, 97-110.

Shur, F. 1901. 'Über die Grundlagen der Geometrie', Mathematiche Annalen, 55, 256.

Sommer, J. 1900. 'Hilbert's foundations of geometry', Bulletin of the American Mathematical Society, 6, 287-299.

Thiele, R. 2003. 'Hilbert's twenty-fourth problem', American Mathematical Montbly, 110, 1-24.

Veblen, O. 1903. 'Hilbert's foundation of geometry', The Monist, 13, 303309.

Veblen, O. 1904. 'A system of axioms for geometry', Transaction of the American Mathematical Society, 5, 439-441.

Venturi, G. 2011. 'Hilbert, completeness and geometry', Rivista di Filosofia Analitica Junior, 2, 80-102.

Manuscrito - Rev. Int. Fil., Campinas, v.40, n.2, pp.5-17, abr.jun. 2017. 